\title{
Las problemáticas ambientales y su recepción en recientes fallos de la Corte Suprema de Justicia de la Nación
}

\author{
Por Stinco Juan
}

\section{Introducción}

Desde la creación de la Secretaría de Juicios Ambientales en el ámbito de la Corte Suprema de Justicia de la Nación, se ha percibido una creciente actividad jurisprudencial en la materia. A partir de la incorporación de especialistas y de la jerarquización de la función, extremo esperado -dado la precedente elevada consideración de estos tópicos por nuestro máximo Tribunal- resulta interesante describir la evolución actual de la jurisprudencia ambiental.

Con tal propósito, pasaremos breve revista a los fallos que consideramos más relevantes dictados por la Corte Suprema durante los años 2015 y 2016 ${ }^{1}$, finalizando con algunos comentarios a modo de conclusiones. Con tal propósito, hemos seguido un orden de asociación temática, y en esta oportunidad decidimos agruparlos por su preponderante importancia en materia procesal o en los aspectos sustanciales por la aplicación central de algún principio específico de la materia.

\section{A) Precedentes que ajustan los rigorismos procesales a la materia ambiental}

1. La excepción de defecto legal respecto de las demandas ambientales debe tener una interpretación adecuada que no impida la tutela del bien colectivo.

En la causa CSJ 1569/2004 (40-M)/CS1, autos "Mendoza, Beatriz Silvia y otros e/ Estado Nacional y otros s/ daños y perjuicios - daños derivados de la contaminación ambiental del Rio Matanza Riachuelo" ${ }^{2}$, en lo que constituyó un avance procesal del expediente principal vinculado con el saneamiento de la Cuenca Matanza-Riachuelo,

1 El relevamiento de caso fue realizado directamente de la página web oficial del máximo tribunal. https://sj.csjn.gov.ar/sj/

2Disponible en

http://sjconsulta.csjn.gov.ar/sjconsulta/documentos/verUnicoDocumentoLink.html?idAnalisis=7 19027 
en fecha 19/2/2015 nuestro máximo Tribunal dictó auto donde tuvo por contestadas las demanda y analizó la excepción de defecto legal opuesta por las demandadas.

Nuestro máximo Tribunal rechazó dicha excepción afirmando que corresponde rechazar la excepción de defecto legal si la forma en que la actora ha planteado su reclamo -a pesar de lo escueto de la narración de los hechos ocurridos y de la genérica imputación de responsabilidad efectuada-, no le impidió de manera alguna a los codemandados el ejercicio amplio de su defensa, tal como de modo manifiesto se desprende de las contestaciones respectivas. Ello es así, pues no hay estado de indefensión si la cosa demandada ha sido denunciada con precisión con lo que no surgen dudas respecto del alcance de la pretensión de la actora y de las posibilidades de los demandados de plantear las defensas que estimen pertinentes... Que, por el contrario, la eventual admisión en el caso de la defensa de defecto legal importaría alterar esencialmente el espíritu de la demanda que se sustenta en las normas del artículo 41 de la Constitución Nacional y en la Ley 25.675 General del Ambiente. Y no hay dudas de que la presente causa tiene por objeto la defensa del bien de incidencia colectiva configurado por el ambiente. En este caso, los actores reclaman como legitimados extraordinarios para la tutela de un bien colectivo, el que por naturaleza jurídica, es de uso común, indivisible, ya que primero corresponde la prevención, luego la recomposición y -en ausencia de toda posibilidad, dará lugar al resarcimiento (Fallos: 329:2316).

Asimismo reiteró el criterio procesal que debe primar en las causas ambientales. En efecto, expresó la Corte que

(...) en este orden de ideas, como lo estableció el Tribunal en el recordado precedente de Fallos: 329: 3493, en asuntos concernientes a la tutela del daño ambiental las reglas procesales deben ser particularmente interpretadas con un criterio amplio que ponga el acento en el carácter meramente instrumental de medio a fin, revalorizando las atribuciones del Tribunal al contar con poderes que exceden la tradicional versión del "juez espectador"... De ello se deriva que la aplicación mecánica o literal del Código de rito para imputar defecto legal a una demanda cuya pretensión responde a presupuestos sustanciales diversos de aquellos que se tuvieron en mira al dictar la normativa procedimental, peca de excesivo rigorismo formal, que se 
opone en forma manifiesta al artículo 41 de la Constitución Nacional y a la ley 25.675 General del Ambiente.”

\section{La intervención de terceros en los procesos ambientales}

Nuestro máximo Tribunal determinó que, en los procesos colectivos y en materia ambiental, existen límites a intervenciones de terceros.

Ello aconteció en la causa CSJ 61/2011 (47-S)/CS1, autos "Santiago del Estero, Provincia de c/Cia. Azucarera Concepción S.A. y otro si amparo ambiental" sentencia de fecha 13/05/2015, donde la firma CreaLab S.R.L. se presentó y solicitó que se le dé participación en el proceso con el objeto de informar al Tribunal acerca de las gestiones realizadas para concretar la planta de tratamiento integral y definitivo para las vinazas, y sobre las dificultades que impiden la concreción del proyecto y su solución.

Ante tal presentación nuestro máximo tribunal sostiene que:

no es difícil concluir que la presentación que se realiza es ajena a la relación procesal ambiental de este expediente, y que, por su propia naturaleza, debe ser instada ante las autoridades gubernamentales, para que ellas, dentro de los procesos legales, administrativos y licitatorios que resultan aplicables e ineludibles, adopten las decisiones que pudiesen corresponder.

\section{Resulta necesario un empleo riguroso de las facultades ordenatorias en los procesos ambientales}

Por otro lado, respecto de las "facultades ordenatorias" en los procesos ambientales, nuestro máximo Tribunal aclaró que las ellas se encuentran reconocidas en el artículo 32 de la ley 25.675 General del Ambiente al Tribunal y en las causas vinculadas a la recomposición del ambiente dañado, deben ser ejercidas con rigurosidad. Causa CSJ 641/2011 (47-A)/CS1, autos "ACUMAR s/ Ordenamiento Territorial", sentencia de fecha $02 / 06 / 2015$.

3 Disponible en http://sjconsulta.csjn.gov.ar/sjconsulta/documentos/verUnicoDocumentoLink.html?idAnalisis=7216 37

4 Disponible en http://sjconsulta.csjn.gov.ar/sjconsulta/documentos/verUnicoDocumentoLink.html?idAnalisis=7221 70 


\section{Los principios preventivos y precautorios en las medidas cautelares dentro del proceso de amparo}

En las causas CSJ 154/2013 (49-C)/CS1 y CSJ 695/2013 (49-C)/CS1, en autos "Cruz, Felipa y otros c/ Minera Alumbrera Limited y otro s/ sumarísimo" 5 , sentencia de fecha 23/02/2016, la Corte expresó que

(...) en primer término, cabe recordar que las resoluciones que se refieren a medidas cautelares, ya sea que las ordenen, modifiquen o extingan, no autorizan el otorgamiento del recurso extraordinario ya que no revisten -como regla- el carácter de sentencias definitivas, principio que -en casos como el presente- admite excepción cuando la medida dispuesta es susceptible de producir un agravio al medio ambiente que, por su magnitud y circunstancias de hecho, puede ser de tardía, insuficiente o imposible reparación ulterior. En ese sentido, no puede dejar de señalarse que en el particular ámbito de las demandas encuadradas en las prescripciones de la Ley General del Ambiente, la interpretación de la doctrina precedentemente enunciada debe efectuarse desde una moderna concepción de las medidas necesarias para la protección del medio ambiente, pues el arto $4^{\circ}$ de esa ley introduce en la materia los principios de prevención del daño ambiental y de precaución ante la creación de un riesgo con efectos desconocidos y por tanto imprevisibles... Es a la luz de estos principios -que apuntan a constituir a las medidas cautelares en medios idóneos para hacer efectivos los propósitos y fines perseguidos por el art. 41 de la Constitución Nacional... que deben entenderse las facultades que el arto 32 de la Ley General del Ambiente otorga a la autoridad judicial interviniente con el objeto de disponer todas las medidas necesarias para ordenar, conducir o probar los hechos dañosos en el proceso, a fin de proteger efectivamente el interés general. En igual sentido debe interpretarse el último párrafo de ese artículo en cuanto dispone que en cualquier estado del proceso, aun con carácter de medida precautoria, podrán solicitarse medidas de urgencia, que el juez también podrá disponer sin petición de parte, aun sin audiencia de la parte contraria, prestándose debida caución por los daños y perjuicios que pudieran producirse...."

5 Disponible

en http://sjconsulta.csjn.gov.ar/sjconsulta/documentos/verDocumentoByIdLinksJSP.html?idDocument $\mathrm{o}=7283852$ 


\section{Asimismo agregó}

Que al omitir toda referencia a la prueba aludida, la Cámara no realizó un balance provisorio entre la perspectiva de la ocurrencia de un daño grave e irreversible y el costo de acreditar el cumplimiento de las medidas solicitadas, principalmente, a la luz del ya citado principio precautorio, conforme al cual, cuando haya peligro de daño grave e irreversible la ausencia de información o certeza científica no deberá utilizarse como razón para postergar la adopción de medidas eficaces, en función de los costos, para impedir la degradación del ambiente -arto $4^{\circ}$ de la ley 25.675-(Fallos: 333:748, disidencia de los jueces Fayt, Maqueda y Zaffaroni)... el juicio de ponderación al que obliga la aplicación del principio precautorio, exige al juez considerar que todo aquel que cause daño ambiental es responsable de restablecer las cosas al estado anterior a su producción (art. 41 de la Constitución Nacional, art. 27 de la ley 25.675 y artículo 263 del Código de Minería). En ese sentido, esta Corte ha sostenido que el reconocimiento de status constitucional del derecho al goce de un ambiente sano, así como la expresa y típica previsión atinente a la obligación de recomponer el daño ambiental (art. 41 de la Constitución Nacional) no configuran una mera expresión de buenos y deseables propósitos para las generaciones del porvenir, supeditados en su eficacia a una potestad discrecional de poderes públicos, federales o provinciales, sino la precisa y positiva decisión del constituyente de 1994 de enumerar y jerarquizar con rango supremo a un derecho preexistente (Fallos: 329:2316)...”.

\section{Flexibilidad en los recaudos procesales vinculados con las vías recursivas en los procesos ambientales}

En la causa CSJ 1314/2012 (48-M) /CS1, autos "Martínez, Sergio Raúl c/ Agua Rica LLC Suco Argentina y su propietaria Yamana Gold Inc. Y otros s/ acción de amparo" ${ }^{6}$, sentencia de fecha 02/03/2016, sostuvo la Corte que

En el caso, concurren las circunstancias excepcionales que permiten superar dicho óbice formal, pues de las constancias de la causa, especialmente, de la resolución 35/09 de la Secretaría de Estado de Minería de la Provincia de Catamarca, se desprende que la medida

6 Disponible

en http://sjconsulta.csjn.gov.ar/sjconsulta/documentos/verDocumentoByIdLinksJSP.html?idDocument $\mathrm{o}=7285524$ 
dispuesta es susceptible de producir un agravio al medio ambiente que, por su magnitud y circunstancias de hecho, puede ser de tardía, insuficiente o imposible reparación ulterior. En efecto, de la resolución mencionada -por la cual se aprobó el Informe de Impacto Ambiental presentado por la Minera Agua Rica LLC para la etapa de explotación del proyecto en carácter de Declaración de Impacto Ambiental- surge que la provincia demandada admitió la existencia de problemas ambientales que la empresa debía solucionar antes del inicio de los trabajos, tanto respecto del área de mina Andalgalá, como del área de proceso Campo Arenal... asimismo, corresponde habilitar el remedio federal pues se verifica una excepción a la regla dispuesta por esta Corte según la cual los pronunciamientos por los que los superiores tribunales provinciales deciden acerca de los recursos de orden local no son, en principio, susceptibles de revisión por medio de la apelación federal por revestir carácter netamente procesal. En tal sentido, procede la excepción cuando lo resuelto por los órganos de justicia locales no constituye una derivación razonada del derecho vigente con arreglo a las circunstancias de la causa (Fallos: 330:4930 y 333:1273), o se realiza un examen de los requisitos que debe reunir la apelación con inusitado rigor formal que lesiona garantías constitucionales (Fallos: 322:702; 329:5556; 330:2836).

\section{Agregó que}

En el caso, el superior tribunal local, al rechazar la vía casatoria por ausencia de sentencia definitiva, omitió dar respuesta a planteas de los actores conducentes para la solución del caso, tendientes a demostrar que la acción de amparo era la vía adecuada para cuestionar la resolución 35/09. Concretamente, y a lo que al caso interesa, no consideró que la elección de dicha vía, como remedio judicial expeditivo, se fundó en los daños inminentes al medio ambiente que puede provocar la aprobación del "Informe de Impacto Ambiental" presentado por la Minera Agua Rica LLC mediante la resolución 35/09, sin haberse salvado en forma previa las objeciones señaladas en el mismo acto por la autoridad de aplicación. En ese sentido, el tribunal a qua debió advertir que la actora alegó que la legislación vigente solo faculta a la autoridad administrativa para aprobar o rechazar el Informe de Impacto Ambiental presentado por las empresas responsables, mas no para aprobarlo condicionalmente, como lo hizo la provincia demandada, así como el invocado inicio de la actividad de explotación por parte de la empresa Minera Agua Rica LLC(...). 
Por ello afirmó que

En tal contexto, no puede desconocerse que en asuntos concernientes a la tutela del daño ambiental, las reglas procesales deben ser interpretadas con un criterio amplio que, sin trascender el límite de su propia lógica, ponga el acento en su carácter meramente instrumental de medio a fin, qué en esos casos se presenta una revalorización de las atribuciones del tribunal al contar con poderes que exceden la tradicional versión del juez espectador (Fallos: 329:3493).

\section{Además expresó que}

(...) es importante señalar que en cuestiones de medio ambiente, cuando se persigue la tutela del bien colectivo, tiene prioridad absoluta la prevención del daño futuro (Fallos: 329:2316). En ese sentido, la realización de un estudio de impacto ambiental previo al inicio de las actividades no significa una decisión prohibitiva del emprendimiento en cuestión, sino antes bien una instancia de análisis reflexivo, realizado sobre bases científicas y con participación ciudadana(...).

Por ello hizo lugar a la queja, declaró formalmente procedente el recurso extraordinario y dejó sin efecto la sentencia apelada.

Lo propio aconteció en la causa CSJ 2810/2015/RHI, autos "Custet Llambí, María Rita -Defensora General- s/ amparo" 7 , sentencia de fecha 11/10/2016, donde el Superior Tribunal de Justicia de la Provincia de Río Negro declaró mal concedido el recurso de revocatoria interpuesto por la Defensora General de dicho Estado local contra la sentencia que hizo lugar a la acción de amparo colectivo.

La Corte entendió que en el caso concurren las circunstancias que permiten superar dicho óbice formal, pues en principio, la posibilidad de que la actora pueda replantear por otra vía procesal el análisis y resolución de la controversia resultaría ilusoria, ya que -tal como surge del relato efectuado- al declarar mal concedido el recurso de revocatoria, el Superior Tribunal provincial convalidó la sentencia que resolvió sobre el fondo del asunto. En efecto, al decidir del modo en que lo hizo, el tribunal a quo omitió ponderar que el juez del amparo había rechazado tácitamente las medidas de remediación de la zona afectada solicitadas por la actora, motivo por el

$7 \quad$ Disponible

en http://sjconsulta.csjn.gov.ar/sjconsulta/documentos/verDocumentoByldLinksJSP.html?idDocument $\mathrm{o}=7339652$ 
cual, en su caso y con acierto, se podría oponer la autoridad de cosa juzgada (Fallos: 335:361).

Por lo demás, también ponderó la Corte que al momento de decidir sobre la procedencia del recurso de revocatoria, la situación ambiental llevaba un prolongado tiempo sin resolver e incidía negativamente en la salud de niñas, niños y adolescentes que habitan las zonas afectadas, lo cual demuestra que los efectos de la sentencia apelada son susceptibles de causar agravios al medio ambiente que, por su magnitud y circunstancias de hecho, pueden resultar de tardía, insuficiente o imposible reparación ulterior.

Asimismo señaló que

En el caso, el Superior Tribunal local, al declarar mal concedido el recurso de revocatoria, prescindió de dar respuesta a planteas de la actora, conducentes para la solución del caso, tendientes a demostrar que dicho recurso era la vía adecuada para la tutela de los derechos invocados. Especialmente, omitió considerar que la interposición del remedio procesal aludido se fundó en que la acción de amparo había sido parcialmente denegada por el magistrado interviniente y que, en consecuencia, su decisión era susceptible de ser apelada por esa vía, en los términos de los arts. 20 de la ley B 2779 Y 43 de la ley K 2430. En efecto, los agravios de la actora en su recurso de revocatoria ante el Superior Tribunal en pleno se centraron en que, al resolver del modo en que lo hizo, el juez del amparo se apartó del objeto de la demanda, en violación al principio de congruencia (...)

Por ello hizo lugar a la queja, se declaró formalmente procedente el recurso extraordinario y se dejó sin efecto la sentencia apelada.

6. La relevancia del impacto ambiental exige que la Corte, como custodio de las garantías constitucionales, ejerza el control encomendado a la Justicia sobre las actividades de los otros poderes del Estado

En la Causa CSJ 5258/2014, autos "Asociación Argentina de Abogados Ambientalistas de la Patagonia e/ Santa Cruz, Provincia de y otro s/ amparo ambiental”, sentencia de fecha 26/04/2016 nuestro máximo Tribunal afirmó que

8 Disponible

en http://sjconsulta.csjn.gov.ar/sjconsulta/documentos/verDocumentoByIdLinksJSP.html?idDocument $\mathrm{o}=7300612$ 
(...) ello exige de esta Corte el ejercicio del control encomendado a la justicia sobre las actividades de los otros poderes del Estado... La Constitución Nacional tutela al ambiente de modo claro y contundente y esta Corte Suprema ha desarrollado esa cláusula de un modo que permite admitir la existencia de un componente ambiental del estado de derecho... Por esta razón, cabe señalar que la efectividad que se reclama para todos los derechos fundamentales, también debe ser predicada respecto de los de incidencia colectiva y en particular del ambiente... Ello es así, pues le corresponde al Poder Judicial de la Nación buscar los caminos que permitan garantizar la eficacia de los derechos, y evitar que estos sean vulnerados, como objetivo fundamental y rector a la hora de administrar justicia y de tomar decisiones en los procesos que se someten a su conocimiento...No debe verse en ello una intromisión indebida del Poder Judicial cuando lo único que hace es tender a tutelar derechos, o suplir omisiones en la medida en que dichos derechos pueden estar lesionados... Que de tal manera, el Tribunal como custodio que es de las garantías constitucionales, y con fundamento en la Ley General del Ambiente, en cuanto establece que "el juez interviniente podrá disponer todas las medidas necesarias para ordenar, conducir o probar los hechos dañosos en el proceso, a fin de proteger efectivamente el interés general" (artículo 32, ley 25.675), ordenará las medidas que se disponen en la parte dispositiva de este pronunciamiento.

Por ello, previo a la definición de su competencia, el máximo Tribunal ordenó medidas preliminares sin que exista óbice procesal alguno.

Asimismo, dicho criterio se observó en la causa CSJ 642/2010 (46-A)/I, autos "Administración de Parques Nacionales c/ San Luis, Provincia de s/ incidente de medida cautelar", sentencia de fecha 04/08/2016, donde la Corte, como custodio que es de las garantías constitucionales, y con fundamento en la Ley General del Ambiente, en cuanto establece que "el juez interviniente podrá disponer todas las medidas necesarias para ordenar, conducir o probar los hechos dañosos en el proceso, a fin de proteger efectivamente el interés general" (artículo 32, ley 25.675), ordenó requerir a la Administración de Parques Nacionales que en el plazo de treinta (30) días presente un informe al Tribunal respecto de cuáles fueron las medidas adoptadas y, en su caso, si se otorgaron autorizaciones y con qué fundamentos.

9 Disponible http://sjconsulta.csjn.gov.ar/sjconsulta/documentos/verUnicoDocumentoLink.html?idAnalisis=732 275 
Lo propio también aconteció en la causa CSJ 121/2009 (45-F)/CS1, autos "Fundación Ciudadanos Independientes c/ San Juan, Provincia de, Estado Nacional y otros s/ acción ambiental meramente declarativa" ${ }^{10}$, sentencia de fecha 20/09/2016.

En efecto, la Corte Suprema expresó

Que los hechos que se denuncian exigen de esta Corte el ejercicio del control encomendado a la justicia sobre las actividades de los otros poderes del Estado y, en ese marco, la adopción de las medidas conducentes que, sin menoscabar las atribuciones de estos últimos, tiendan a sostener la observancia de la Constitución Nacional, más allá de la decisión que pueda recaer en el momento en que se expida sobre su competencia para entender en el caso por vía de la instancia prevista en el artículo 117 de la Constitución Nacional... Ello es así, pues le corresponde al Poder Judicial de la Nación buscar los caminos que permitan garantizar la eficacia de los derechos, y evitar que estos sean vulnerados, como objetivo fundamental y rector a la hora de administrar justicia y de tomar decisiones en los procesos que se someten a su conocimiento. No debe verse en ello una intromisión indebida del Poder Judicial cuando lo único que hace es tender a tutelar derechos, o suplir omisiones en la medida en que dichos derechos puedan estar lesionados (Fallos: 328: 1146).

De este modo, nuestro máximo Tribunal como custodio que es de las garantías constitucionales, y con fundamento en la Ley General del Ambiente, en cuanto establece que "el juez interviniente podrá disponer todas las medidas necesarias para ordenar, conducir o probar los hechos dañosos en el proceso, a fin de proteger efectivamente el interés general" (art. 32, ley 25.675), ordenó, sin perjuicio de lo que en definitiva se decida, requerir a la Provincia de San Juan, que en el plazo de veinte (20) días informe al Tribunal diversos hechos y actividades de relevancia.

\section{Restricción en la competencia originaria de la Corte Suprema en procesos ambientales}

En contraste con las novedades de vanguardia mencionadas, en la causa CSJ 5258/2014, autos "Asociación Argentina de Abogados Ambientalistas de la Patagonia

10 Disponible en http://sjconsulta.csjn.gov.ar/sjconsulta/documentos/verUnicoDocumentoLink.html?idAnalisis=733 617 
e/ Santa Cruz, Provincia de y otro s/ amparo ambiental"11, sentencia de fecha 21/12/2016, nuestro máximo Tribunal restringe su competencia originaria con sustento en la tradicional jurisprudencia en la materia.

En efecto, afirmo la Corte Suprema que

(...) en lo que se refiere a la determinación de la competencia originaria de esta Corte, cabe señalar que el alcance de la pretensión no permite atribuirle a la Provincia de Santa Cruz el carácter de parte adversa, pues el objeto del litigio demuestra que es el Estado Nacional el sujeto pasivo legitimado que integra la relación jurídica sustancial, en tanto la ejecución de obra denominada "Aprovechamientos Hidroeléctricos del Río Santa Cruz Presidente Dr. Néstor Carlos Kirchner - Gobernador Jorge Cepernic", se encuentra sometida a su jurisdicción... En efecto, no obstante las relaciones de naturaleza interestadual emergentes de dicho convenio, que constituye un instrumento para coordinación de esfuerzos y funciones dirigidos al bien común general, el objeto de que trata esta causa y sobre el que deberá expedirse la sentencia se vincula exclusivamente con el Estado Nacional y con su eventual obligación de cumplir con el procedimiento de evaluación de impacto ambiental previsto en la Ley Nacional de Obras Hidráulicas 23.879... En tales condiciones, el alcance de la pretensión determina que el Estado Nacional es el único que resultaría obligado y con posibilidades de cumplir con el mandato restitutorio del derecho que se denuncia como violado, en el supuesto de admitirse la demanda, esto es, la realización del estudio de impacto ambiental y la audiencia pública que se denuncian omitidas (arg. Fallos: 330:555, considerando $7^{\circ} ; 333: 479 ; 334: 1143$ y 1342$) ”$.

Empero, también señala el máximo Tribunal que sin perjuicio la no procedencia de la competencia originaria, con la finalidad de impedir la perduración de situaciones que de mantenerse en el tiempo podrían llegar a configurar un caso de privación jurisdiccional para las partes, es necesario en esta instancia determinar qué juez debe intervenir en estas actuaciones resultando federal de la Ciudad Autónoma de Buenos Aires, lugar en el que, llegado el caso, debería cumplirse la obligación de hacer reclamada por la parte actora.

11 Disponible en http://sjconsulta.csjn.gov.ar/sjconsulta/documentos/verUnicoDocumentoLink.html?idAnalisis=735 251 
Por ello la Corte Suprema resolvió hacer lugar a la medida cautelar solicitada y, en consecuencia, se ordena la suspensión de las obras "Aprovechamientos Hidroeléctricos del Río Santa Cruz Presidente Dr. Néstor Carlos Kirchner - Gobernador Jorge Cepernic" hasta que se implemente el proceso de evaluación de impacto ambiental y audiencia previsto en la ley 23.879, o hasta el dictado de la sentencia definitiva, lo que suceda en primer término y, asimismo declaró que la presente causa resulta ajena a la competencia de esta Corte prevista en los artículos 116 Y 117 de la Constitución Nacional, determinando la competencia de la justicia nacional en lo contencioso administrativo federal de la Ciudad Autónoma de Buenos Aires para entender en la presente causa.

\section{Criterios sobre competencia. Las problemáticas ambientales son complejas}

En la Causa CSJ 265/2014 (50-C)/CSJ autos "U.F.I.M.A. s/Denuncia"12 en fecha 23/02/2016 la Corte Suprema resuelve una contienda negativa de competencia producida entre el Juzgado Federal $n^{\circ} 1$ y el Juzgado de Garantías n ${ }^{\circ} 2$, ambos de la localidad de Azul, Provincia de Buenos Aires.

La causa se originó a raíz de la denuncia efectuada por el titular de la Unidad Fiscal de Investigaciones en Materia Ambiental (U.F.I.M.A.) por la presunta infracción al arto 25 de la ley nacional 22.421 de conservación de la fauna silvestre.

En tal sentido, recordó la Corte que la declaración de incompetencia debe hallarse precedida de una adecuada investigación, tendiente a determinar concretamente en qué figura delictiva encuadra el hecho denunciado (las declaraciones de incompetencia deben contener la individualización de los hechos sobre los cuales versa y las calificaciones que le pueden ser atribuidas) pues solo respecto de un delito concreto cabe analizar la facultad de investigación de uno u otro juez, circunstancia que no se presenta en autos.

En segundo término, sostuvo el Tribunal cimero, se debe reparar -si fuera una decisión circunscripta únicamente a la ley 22.421- que se desconocería cuáles serían las especies ofrecidas más allá de las que se exhiben en la página web; estas últimas protegidas a nivel nacional por la mencionada ley de fauna y a nivel internacional por la Convención sobre el Comercio Internacional de Especies Amenazadas de Fauna y Flora Silvestre (CITES). Por su parte, manifestó el Tribunal que tampoco se sabe si los animales podrían ser capturados en otras provincias y que en este sentido, hay que mencionar que el art. $1^{\circ}$ de la ley 22.421 declara de interés público la fauna que habita en el territorio de la República Argentina.

12 Disponible

en http://sjconsulta.csjn.gov.ar/sjconsulta/documentos/verDocumentoByIdLinksJSP.html?idDocument $\mathrm{o}=7282663$ 
Además, la Convención sobre el Comercio Internacional de Especies Amenazadas de Fauna y Flora Silvestre (CITES), reconoce que la "fauna silvestre", en sus variadas formas, constituye "un elemento irremplazable en los sistemas naturales de la tierra, tiene que ser protegida por esta generación y las venideras". Y establece que la cooperación internacional es esencial para la protección de ciertas especies de la misma "contra su explotación excesiva mediante el comercio internacional". Que en dicha convención, aprobada por ley 22.344 (decreto reglamentario 522/1997), las especies se encuentran incluidas en listados, denominados "Apéndices I, II Y III", según su grado de amenaza. En ese sentido, se destaca que los ejemplares de la fauna silvestre involucrados están incluidos en dichos apéndices de CITES.

Adicionalmente, analizó la Corte Suprema, el caso presentaría otras hipótesis de delitos federales.

De este modo entendió que las investigaciones criminales deben abarcar la totalidad de las implicancias y consecuencias de la conducta denunciada y no acotarlas al análisis de un único tipo penal.

Por ello declaró que deberá entender en la causa en la que se originó la presente cuestión de competencia el Juzgado Federal $n^{\circ} 1$ de Azul, Provincia de Buenos Aires.

A su vez, las figuras delictivas vinculadas con temas ambientales, por su complejidad, pueden involucrar a funcionarios de diversas jurisdicciones. En estos supuestos corresponde la escisión de las causas y mantener el fuero federal exclusivamente para los funcionarios federales.

En efecto, en la causa CSJ 4861/2015/CSJ autos: "Actuaciones remitidas por Fiscalía Única de Jáchal s/ con motivo de la denuncia de Saúl Argentino Zeballos y denuncia de Fiscalía de Estado - denuncia Defensoría del Pueblo"13, sentencia de fecha 05/05/2016, se resolvió un conflicto de contienda positiva de competencia entre el Juzgado Letrado de Jáchal, Provincia de San Juan y el Juzgado Nacional en lo Criminal y Correccional Federal $n^{\circ} 7$ de esta ciudad, como consecuencia de la investigacióndel derrame de solución cianurada en el río Potrerillos que se produjo desde la mina Veladero, ubicada en el Departamento de Iglesia de la Provincia de San Juan, y operada por la empresa "Barrick Gold". Por el mismo episodio se originaron dos procesos penales en distintas jurisdicciones.

13 Disponible

en http://sjconsulta.csjn.gov.ar/sjconsulta/documentos/verDocumentoByldLinksJSP.html?idDocument $\mathrm{o}=7304592$ 
Así sostuvo la Corte Suprema que

(...) sobre la base de lo expuesto, resultaría adecuado escindir la investigación por la presunta infracción a la ley 24.051 respecto de los directivos de la empresa "Barrick Gold" y de los funcionarios locales por un lado, y por el otro la investigación exclusivamente sobre la posible responsabilidad de Sergio Lorusso y Jorge Mayoral relacionada con sus funciones de estricto carácter federal... Toda vez que el objeto procesal de la causa de Jáchal se circunscribe a determinar la responsabilidad de los ejecutivos de la empresa Barrick Gold por el delito previsto y reprimido en el arto 56 de la ley 24.051 y examinar la debida actuación de los funcionarios provinciales, correspondería a dicho tribunal continuar con la investigación de estos hechos...”.

Por ello se declaró que en la causa $\mathrm{n}^{\circ}$ 10049/15 del Juzgado Nacional en lo Criminal y Correccional Federal $\mathrm{n}^{\circ} 7$ de esta ciudad deberá continuarse la investigación exclusivamente respecto de Sergio Lorusso -ex Secretario de Ambiente de la Nación- y Jorge Mayoral ex Secretario de Minería de la Nación- y/o de los otros funcionarios federales que pudiese corresponder y que por su parte, en la causa $n^{\circ}$ $33550 / 15$ y acumulados n 33551/15 caratulada "Actuaciones remitidas por Fiscalía Única de Jáchal con motiva de la denuncia de Saúl Argentino Zeballos y denuncia de Fiscalía de Estado", deberá entender el titular del Juzgado Letrado de Jáchal, Provincia de San Juan.

Para finalizar la Corte expresó

Debe finalmente llamarse la atención para que se eviten en el futuro procedimientos similares al adoptado en el presente conflicto, que solo concurren en detrimento de una rápida y buena administración de justicia. En efecto, se trata de evitar excesos de la jurisdicción federal que perjudican las competencias que de acuerdo a la organización federal de nuestro estado, han sido asignadas a las provincias (artículo 50 de la Constitución Nacional).

Finalmente podemos citar lo resuelto en la causa CSJ 3570/2015/CSI, autos "Asociación Civil Protecc. Ambiental del Río Paraná Ctrol. de Contam. Y 
Restauración del Hábitat y otro c/ Carboquímica del Paraná S .A. Y otro/a s/ amparo" ${ }^{14}$, sentencia de fecha 29/03/2016.

Según surge de la demanda los actores denunciaron que "se vierten al río Paraná, a través de los efluentes líquidos de Carboquímica del Paraná S. A., residuos industriales altamente contaminantes...".

Con tales consideraciones fácticas, la Corte sostuvo que

(...) Por lo tanto, se encontraría afectado el río Paraná, que constituye un recurso hídrico interjurisdiccional, perteneciente a la Cuenca Hídrica del Plata (art. $2^{\circ}$ de la ley 25.688; Régimen de Gestión Ambiental de Aguas). El cauce del río Paraná, recorre diversas provincias del país, hasta desembocar en el Río de La Plata. Asimismo, la vía fluvial mencionada constituye el límite natural entre las provincias de Buenos Aires y Entre Ríos, extremo que coadyuva en el carácter interjurisdiccional del recurso presuntamente afectado (arg. Art. $7^{\circ}$ segundo párrafo de la ley 25.675, Ley General del Ambiente)... La existencia de la alegada contaminación surgiría de la documentación que obra en la causa emanada de la Dirección Prevención Ecológica y Sustancias Peligrosas de la Superintendencia de Seguridad Siniestral dependiente del Ministerio de Seguridad de la Provincia de Buenos Aires (fs. 10/16); de la Oficina de Gabinete de Apoyo Técnico de la división operaciones del Departamento Delitos Ambientales dependiente de la Policía Federal Argentina (fs. 19/21), y del Organismo Provincial para el Desarrollo Sostenible de la Provincia de Buenos Aires (fs. 22/24)"

Así declaró que resulta competente para conocer en las actuaciones el Juzgado Federal de Primera Instancia ${ }^{\circ} 1$ de San Nicolás.

B) Precedentes que hacen a la adecuación de aspectos sustanciales a través de la aplicación de principios especiales propios del Derecho Ambiental.

1. Dominio y jurisdicción no son lo mismo. La protección ambiental como prioridad. La normativa ambiental de carácter nacional encuentra sustento en las competencias reconocidas al Congreso Nacional en el inc. 30 del art. 75 de la Constitución Nacional.

14 Disponible

en http://sjconsulta.csjn.gov.ar/sjconsulta/documentos/verDocumentoByIdLinksJSP.html?idDocument $\mathrm{o}=7291442$ 
En la causa CSJ 957/2008 (44-M)/CSl, autos "Misiones, Provincia de el Estado Nacional y otro s/ nulidad de acto administrativo" ${ }^{15}$, sentencia de fecha 13/05/2015 la cuestión de fondo consistía en dilucidar si la Administración de Parques Nacionales ejerce jurisdicción en el lugar y si, en consecuencia, es competente como autoridad de aplicación de la ley 22.351 para admitir o rechazar el proyecto "Globo Aerostático Cautivo"; o si por el contrario, por tratarse de un inmueble de la provincia tal decisión está fuera de la órbita de su competencia".

Para resolver dicho conflicto afirmó que

Que el hecho de que el inmueble pertenezca al dominio de la provincia hecho no controvertido en el caso, tal como ha quedado expuesto-, no obsta a la aplicación de la ley 22.351. El ejercicio de la jurisdicción que le compete a las autoridades nacionales se sustenta en el hecho de que el bien, se encuentra emplazado en la Reserva Nacional Iguazú, y aquél no se ve limitado porque el bien está en cabeza de otras personas, pues dominio y jurisdicción no son conceptos equivalentes y correlativos (Fallos: 154:312); a tal punto que el Gobierno de la Nación puede tener absoluta y exclusiva jurisdicción, sin necesidad de que los lugares le pertenezcan en propiedad (Fallos: 21:491 y 321:1052)... Que el legislador ponderó la necesidad de declarar como Parque Nacional o Reserva Nacional las áreas del territorio de la República Argentina que por su extraordinaria belleza o riqueza en flora y fauna autóctona o en razón de un interés científico determinado, debían ser protegidas y conservadas para investigaciones científicas, educación y goce de las presentes y futuras generaciones, y atribuyó a la autoridad de aplicación las facultades inherentes al cumplimiento de los fines específicos de ese establecimiento creado en los términos del artículo 75, inciso 30, de la Constitución Nacional (v. artículos $1^{\circ}$ y 14 de la ley 22.351)... En efecto, es la Administración de Parques Nacionales la autoridad de aplicación en la Reserva Nacional, y es a ese organismo a quien la ley le impuso deberes y obligaciones, explícitas e implícitas, con arreglo a los fines de su creación; y entre ellos está la autorización y reglamentación de la construcción y funcionamiento de las instalaciones turísticas (su artículo 18, inciso n), como todas aquéllas que sean herramientas útiles para el logro del fin perseguido en la legislación, cual es la conservación de sistemas ecológicos, el mantenimiento de zonas protectoras del Parque

15 Disponible

en http://sjconsulta.csjn.gov.ar/sjconsulta/documentos/verDocumentoByIdLinksJSP.html?idDocument $\mathrm{o}=7213561$ 
Nacional contiguo en los términos previstos en los artículos $9^{\circ}$ y 10 del cuerpo legal en examen.

Por ello concluyó que "Que por esas razones es que el artículo 19 de la ley en examen determina que toda entidad o autoridad pública que realice o deba realizar actos administrativos que se relacionen con la "Administración de Parques Nacionales - Atribuciones y Funciones" debe dar intervención al organismo."

A mayor abundamiento también expresó que

Que respecto al planteo de invalidez de los artículos 10 y 18 de la citada ley 22.351, debe señalarse de conformidad con lo dictaminado por la señora Procuradora Fiscal, que aun cuando los Estados sean dueños de los recursos naturales, (artículo 124, Constitución Nacional), y sólo hayan delegado a la Nación la fijación de los presupuestos mínimos de protección ambiental (artículos 41 y 121, de la Carta Magna), resulta insoslayable que aquellas disposiciones deban aplicarse en el caso, de manera que quede resguardada la previsión contenida en el artículo 75, inciso 30; precepto este último que otorga sustento más que suficiente a la legislación que se impugna y a su aplicación en el caso, en tanto ésta tiende al cumplimiento de los fines específicos del establecimiento.

Con tales sustentos se rechazó la demanda.

\section{La aplicación directa del principio de Cooperación.}

En la causa CSJ 528/2011 (47-C), autos "Comunidad Indigena Toba La Primavera

- Navogoh c/ Formosa, Provincia de y otros si medida cautelar" ${ }^{16}$, sentencia del 07/04/2015, nuestro máximo Tribunal expresó que

(...) cabe instar a las partes a que continúen con la colaboración mutua, que se deben, a fin de que cada una de ellas cuente con los elementos que les permitan valorar adecuadamente las bondades del emprendimiento que se impugna... Que, sin perjuicio de ello, y aun cuando no cabe duda alguna de que la obra se está llevando a cabo en territorio comunitario, se le debe hacer saber a la Comunidad que, en

16 Disponible en http://sjconsulta.csjn.gov.ar/sjconsulta/documentos/verUnicoDocumentoLink.html?idAnalisis=720 565 
esta instancia procesal, no se advierte razón para prohibir la realización de los trabajos que se consideren necesarios para preparar los terrenos de forma que permita avanzar en el fin perseguido, y a la Provincia que, en su caso, se dispondrán las medidas que correspondan (arg. artículos 619 y 620, Código Procesal Civil y Comercial de la Nación). A fin de realizar la valoración consiguiente, corresponde requerirle al Estado provincial que agregue copias certificadas de las carpetas técnicas correspondientes al centro de salud que se construirá en el predio cedido por la señora Evangelina Fonda que les fueron entregadas a los miembros de la Comunidad en la reunión llevada a cabo el 26 de febrero del corriente año, como así también de las actuaciones administrativas vinculadas a dicha obra, en particular, de los antecedentes que dieron lugar a la resolución 2/2014 del Instituto de Comunidades Aborígenes, del 23 de octubre de 2014.

Asimismo, cabe mencionar que la aplicación de este principio incluso trascendió a la conducta de las partes, traspasando fronteras territoriales y nacionales. En efecto, en la causa CSJ 175/2007 (43-V)/CS1, autos "Vargas, Ricardo Mario c/ San Juan, Provincia de y otros si daño ambiental" ${ }^{17}$, sentencia de fecha, 01/09/2015, la parte actora puso en conocimiento de la Corte Suprema que la Corte de Apelaciones de Copiapó de Chile había suspendido la actividad del proyecto minero "Pascua Lama" fundada "en la afectación entre otros ecosistemas, del referido glaciar Toro I de naturaleza binacional y compartido con la Argentina".

De este modo, afirmó nuestra Corte Suprema de Justicia que

(...) en virtud de que las sentencias de la Corte Suprema deben atender a la situación de hecho existente en el momento de su dictado (Fallos: 328:4640; 329:5798 y 5913, entre muchos otros), y en mérito a las singulares características del emprendimiento minero denominado Pascua Lama, de carácter binacional, el Tribunal no puede obviar las decisiones jurisdiccionales adoptadas al respecto en la República de Chile. Cabe recordar en este punto que uno de los principios de política ambiental que establece la Ley General del Ambiente es el de cooperación según el cual "los recursos naturales y los sistemas ecológicos compartidos serán utilizados en forma equitativa y racional" y que "El tratamiento y mitigación de las emergencias ambientales de efectos transfronterizos serán desarrollados en forma conjunta" (artículo

17 Disponible

http://sjconsulta.csjn.gov.ar/sjconsulta/documentos/verUnicoDocumentoLink.html?idAnalisis=724 379 
40 de la ley 25.675) En efecto, la Corte de Apelaciones de Copiapó admitió un recurso de protección de garantías constitucionales interpuesto en los términos previstos en la legislación chilena por comunidades indígenas, en contra de la Compañía Minera Nevada SpA -sociedad relacionada con la matriz Barrick Gold-, La sentencia indicó que "del mérito de los antecedentes recopilados, es posible colegir indubitadamente, que en la especie existe una 'amenaza' seria a los recursos hídricos", Específicamente indicó que se había constatado que la empresa ejecutante no había construido adecuadamente la infraestructura necesaria para el tratamiento de aguas, que no había implementado correctamente las acciones tendientes a mitigar y controlar el material particulado derivado de la no humectación de los caminos cercanos a los glaciares, lo que per se instituía una amenaza a los recursos hídricos del lugar, y advirtió que los cuerpos de hielo Toro 1 y Esperanza mantenían una capa de material particulado de algunos centímetros de espesor lo que generaba un riesgo de daño ambiental que debía cesar en aras a no generar más perjuicios a los bienes jurídicos tutelados, tanto en el orden nacional como internacional (considerandos $7^{\circ}$, SO Y 11 de la sentencia). Así, la Corte de Apelaciones ordenó la paralización de la construcción del proyecto, estableciendo una serie de condiciones para la reanudación de las actividades, por haberse comprobado incumplimientos de la empresa a las previsiones contenidas en la Resolución de Calificación Ambiental (RCA) $n^{\circ}$ 24/2006, que constituye la norma medioambiental que rige específicamente la actividad en el país vecino, y por considerar que existía una amenaza seria a los recursos hídricos ubicados en la zona (sentencia del 15 de julio de 2013, en la causa-rol 300-2012, publicada en la página web del Poder Judicial chileno, www.pjud.cl)

Cabe señalar que nuestro máximo Tribunal ponderó que la decisión referida fue luego confirmada por la Corte Suprema de la República de Chile en la causa-rol 53392013, sentencia del 25 de septiembre de 2013, también publicada en la citada página web.

Por ello la Corte, en virtud de los principios precautorio y de cooperación (artículo $4^{\circ}$ de la ley 25.675), en el marco de las facultades instructorias del juez en el proceso ambiental (artículo 32 de la ley citada), requirió a la empresa demandada, al Subgrupo de Trabajo creado específicamente para temas de Seguridad Minera y tema Medio Ambiental, y a la Provincia de San Juan que presenten información específica sobre lo acontecido. 


\section{Asegurada la participación y el consenso, la voluntad mayoritaria debe primar en materia ambiental}

En la causa CSJ 528/2011 (47-C)/CS2, autos "Comunidad Indígena Toba La Primavera - Navogoh el Formosa, Provincia de y otros si medida cautelar" ${ }^{18}$, sentencia de fecha 15/09/2015, frente al comienzo de la construcción de un centro de salud en un terreno de propiedad comunitaria, y en atención a los cortes de la ruta nacional $\mathrm{n}^{\circ}$ 86 y de caminos vecinos realizados por algunos miembros de la Comunidad Qom Potae Napocna Navogoh en protesta por no haber sido consultados -según esgrimieron- acerca de la obra, esta Corte instó a las partes a que continuaran con la colaboración mutua que se deben, a fin de que cada una de ellas contase con los elementos que les permitieran valorar adecuadamente las bondades del emprendimiento.

$\mathrm{Al}$ respecto sostiene la Corte que

(...) si bien se mantiene vigente la medida cautelar dispuesta a fs. 50/52 por el Juzgado Federal $n^{\circ} 1$ de Formosa, no corresponde atribuirle los alcances pretendidos por el señor Félix Díaz... La medida cautelar en la que pretende apoyarse la oposición, y por la que se suspendieron las tareas que en aquel momento se efectuaban en un terreno de 609 hectáreas, que habían sido destinadas a la construcción de un Instituto Universitario (fs. 51 vta.), no puede ser interpretada sino en consonancia con su finalidad de preservar los derechos que los pueblos indígenas reivindican sobre esas tierras. Desde esa perspectiva, no cabe extender los efectos de esa decisión precautoria a cualquier acto que pretenda realizarse, incluso a la ejecución de una obra que, como en este caso, fue consultada y aprobada por los miembros de la Comunidad por haberla considerado beneficiosa y conveniente... Que ello es así, pues la proporcionalidad, en el sentido de "prohibición de exceso", resulta principalmente significativa para interpretar medidas de injerencia del Estado, tanto de la administración como de los Poderes Legislativo y Judicial (Fallos: 333: 1023)

18 Disponible en http://sjconsulta.csjn.gov.ar/sjconsulta/documentos/verUnicoDocumentoLink.html?idAnalisis=724 727 
De este modo, la CSJN entendió que en tales condiciones, y más allá de las decisiones que en el futuro se tomen sobre el relevamiento territorial que se realizó en este proceso, sería excesivo e irrazonable otorgar a la cautelar en cuestión la amplitud que le pretenden atribuir los peticionarios.

Para ello tuvo especial consideración de que la obra denominada "Construcción Centro de SaludColonia La Primavera - Laguna Naick-Neck - Formosa", tiene elpropósito de fortalecer el sistema de atención médica y sanitariaen la Comunidad, y fue aprobada enla Asamblea del 4 de marzo de 2015, la que contó con la participación de representantes válidos y democráticos de los diversos sectores involucrados, no mediando impugnación alguna.

Por ello se entendió que la obra fue aprobada por los representantes de la Comunidad en pleno conocimiento de que se realizaría dentro del territorio comunitario, que ocuparía una superficie de tres mil quinientos metros cuadrados $(3500 \mathrm{~m} 2)$, que la provincia dictó el acto administrativo respectivo con fundamento en las previsiones contenidas en los artículos 12 y 13 de la Ley Integral del Aborigen $\mathrm{n}^{\circ} 426$ de Formosa (conf. resolución 2/2014 del Instituto de Comunidades Aborígenes, del 23 de octubre de 2014), y que se ubicaría en el predio ocupado por la señora Evangelina Fonda (ver fs. 2337 y presentación de fs. 2362/2370, apartado 11). Sin embargo, ninguna de estas circunstancias mereció objeción alguna en aquella oportunidad.

Por todo ello el Tribunal sostuvo que no se ha aportado elemento alguno de juicio que recomiende impedir la continuación de la obra, máxime cuando, sobre la base de los fundamentos expuestos, corresponde considerar que el procedimiento de consulta al pueblo interesado fue apropiado, dado que se llegó a un acuerdo con los representantes de los distintos sectores de la Comunidad y se logró su consentimiento acerca de las medidas propuestas.

\section{Breves comentarios finales}

El período relevado mostró una Corte Suprema de Justicia muy activa en la materia. Pero no sólo en lo cuantitativo. En efecto, se registraron muchos fallos en materia ambiental, superando los promedios anuales de los años anteriores. Pero el impacto más saliente puede encontrarse en la especialidad que seguramente aportó la Secretaría de Juicios Ambientales.

En particular, logra observarse una tendencia hacia la flexibilización de los rigorismos procedimentales en los pleitos vinculados a la materia ambiental, tanto respecto del escrito de inicio, de las vías procesales adoptadas y también en materia cautelar y recursiva. Sería dable esperar que lo propio acontezca en materia de medios probatorios, y se comience a vislumbrar una mayor injerencia de los métodos 
indirectos, tales como las presunciones hominis, la regla res ipsa loquitur y la doctrina de las cargas probatorias dinámicas.

También cabe resaltar cierta impronta de proactividad del Ministerio Público Fiscal. Esta tendencia que recién se registra en la máxima instancia, seguramente será contrastada de relevarse la actividad en las primeras instancias. Esta saludable participación activa, que encuentra imposición normativa en el art. 120 de la Constitución Nacional y en el 36 de la Ley 27.148, esperamos se profundice en lo sucesivo en aras al cumplimiento de sus objetivos institucionales.

No menos importante resulta el recurrente empleo del principio precautorio en materia ambiental. Conforme entendemos, esta es una nota distintiva del derecho ambiental que justifica su exorbitancia respecto de las restantes ramas del derecho dada la innecesariedad del daño como presupuesto de responsabilidad- a la que se pueden agregar la inconveniencia de una relación de causalidad adecuada y, asimismo, el postulado del principio de prohibición, entre otros aspectos.

La recurrencia a este principio particular del derecho ambiental, como fuente de herramientas y soluciones, resulta muy saludable. Sin perjuicio de ello será necesario que los operadores trabajen en la precisión de los alcances del mismo para no generar un impacto indeseado en materia de seguridad jurídica.

Lo propio cabe señalar del principio de cooperación, y el reconocimiento de que las realidades ambientales no pueden afrontarse a partir de prismas materiales o territoriales exclusivamente. Este principio generó la incorporación de probanzas y precedentes de sistemas jurídicos comparados, aspecto tan interesante como novedoso.

Nuestro máximo Tribunal en términos generales mantiene su posición de vanguardia en la materia. Sin embargo lo que aparecía, en años precedentes, como una tendencia en profundización en materia de competencia originaria de la Corte Suprema parece comenzar un ciclo de restricción. En efecto, en primer lugar cabe señalar por su propia naturaleza las problemáticas ambientales difícilmente respeten límites territoriales provinciales y mantener esa óptica puede llevar a problemáticas adicionales. Por otro lado, la escisión de las pretensiones o bien de las investigaciones no sólo conspira contra un acabado conocimiento integral del conflicto, sino también contra el funcionamiento eficiente del sistema de justicia. Finalmente, el estándar de la titularidad de la relación jurídica a efectos de ponderar la necesariedad de la participación de un Estado provincial, no se corresponde con la materia ambiental, toda vez que más allá de algún supuesto particular, todos los operadores son responsables frente a un daño al bien colectivo denominado Medio Ambiente entendido en su acepción más amplia; si a ello se le suma la potestad regulatoria y la ponderación de los intereses locales resulta evidente que dicho estándar parece desbordado. Naturalmente, existe un correlativo sostén de la posición en el respeto 
del sistema de reparto de competencias que se encuentra en nuestra Carta Magna, y su estricta interpretación en el caso de los art. 116 y 117, sin perjuicio de lo cual la especificidad ambiental deberá desarrollar los instrumentos para lograr una adecuada articulación que evite la frustración de derechos y garantías constitucionales.

También merece comenzar a alertar sobre la efectividad de los mecanismos de participación ciudadana en materia ambiental. En particular cabe tener muy presente el estándar plural que debe garantizarse y, asimismo, una real participación de los actores involucrados y la ponderación adecuada de sus pretensiones y fundamentos en el acto de decisión estatal. Para ello no debe perderse de vista la necesaria regionalización y estratificación de audiencias según tipos de intereses, extremo incluso pendiente en materia de tarifas de servicios públicos.

Conforme sostenemos, el Derecho Ambiental está recorriendo un camino de permanente evolución, profundizando la tutela de los derechos y garantías. Este recorrido encuentra patente correlato en el segmento de fallos de nuestro Máximo Tribunal que hemos seleccionado. 